\title{
THE EFFECT OF POSITIVE PSYCHOLOGICAL CAPITAL PROGRAM ON RETENTION OF NURSES
}

Saisamorn Chaleoykitti, Ann Thaiudom

The Royal Thai Army Nursing College, Bangkok, Thailand

\begin{abstract}
Turnover rate of nurses in Thailand has been increasing due to excessive workload, stressful nature of the work and lack of psychological support. Therefore, the researcher has developed interventions to promote positive psychological strengths to improve retention rates among nurses. The purposes of this study were to examine retention of nurses and the effect of the program to develop positive psychological capital among professional nurses. The samples were randomly divided in two groups: experimental and control groups, consisting of 20 nurses each group. The experimental group received the program, including 16-hour class lectures, counseling and activities designed to reinforce the 5 elements of positive psychological capital: self-efficacy, hope, optimism, resilience and hardiness, while the control group did not. The study found that retention intention of nurses in the experimental group was greater than that of the control group with statistical significance.
\end{abstract}

Keywords : Psychological capital, Retention, Nurses

J Southeast Asian Med Res 2017; 1: 58-62.

http://www.jseamed.org

\section{Correspondence to:}

Chaleoykitti S, The Royal Thai Army Nursing College, Bangkok, Thailand

E-mail : Saisamorn2006@hotmail.com 


\section{Introduction}

Nurses play vital roles in providing health services and ensuring patient safety. Nursing practices are based on a holistic approach, covering health promotion, disease prevention, treatment and rehabilitation requiring nursing knowledge, skills and other integrated relevant sciences. ${ }^{(1,2)}$

Nurses also need to take responsibility for their duties, morality and ethics to provide nursing services and effectively work with multidisciplinary personnel both from internal and external organizations. ${ }^{(3)}$ Nurses working in the hospitals under the Ministry of Defense, especially in Bangkok including Phramongkutklao Hospital, Bhumibol Adulyadej Hospital and Somdej Phra Pin Klao Hospital have to perform their duties both as professional nurses and military personnel. They have to develop military characteristics and work under military discipline, courtesy and probation, follow the chain of command and strict rules and regulations. Further, nurses have been dealing with heavy workloads and shortage of nurses due to limited funding to produce nurses, causing insufficient production, compared with the demand. ${ }^{(1,3,5)}$

Moreover, shortage of nurses and excessive workload problems cause deteriorated health, work dissatisfaction, stress, anxiety, discouraged feelings, uncertainty with their work and less work commitment. ${ }^{(4,5)}$ Further, low salary, delayed professional growth and lack of promotional opportunities in the career path has led nurses to leave the organizations they worked for or change their position to nonnursing health professions, which could negatively affect the healthcare system in the Ministry of Defense.

A number of strategies are used to promote work satisfaction such as improved working environment, increased work freedom and use of the participatory approach. However, psychological concepts are gaining great attention among academics focusing on organizational behaviors. ${ }^{(5,6,7)}$ Apart from external motivation, positive psychological capital is an internal motivation that can be used to motivate nurses to remain in the healthcare system as long as possible, reduce the resignation rate and lower the number of professionals leaving or changing their workplace. ${ }^{(8,9)}$ Once positive psychological capital among personnel in an organization has been developed, nurses, who are significant healthcare providers in developing an organization, would be able to perform their duties with maximum potential, enthusiasm, organizational attachment, contributing to working happiness and passion and better retention in nursing career. ${ }^{(10,11)}$ Thus, the researcher was interested in examining the effect of positive psychological capital on retention of nurses by strengthening psychological capability. ${ }^{(12,13,14)}$ and enhancing organizational attachment and working happiness. ${ }^{(15)}$ The research findings could also be used for nursing administrators to reinforce desirable working outcomes among nurses to improve retention and reduce turnover rates among nursing professionals, important workforce mechanisms driving the healthcare system throughout the country. This would contribute to better quality of life, working happiness and quality of care among the nurses ${ }^{(16)}$, which in turn would benefit professional nurses themselves, the Ministry of Defense and the nation in the future.

\section{Materials and Methods}

The research hypothesis was retention of nurses in the experiment group will improve after completing the program and scores will be greater than in the control group. In this study, purposive sampling was used to select 40 professional nurses in Phramongkutklao Hospital, Somdej Phra Pin Klao Hospital and Phumibol Adulayadej Hospital. Then the subjects were randomly selected to the experimental and control groups consisting of 20 nurses each group. ${ }^{(6)}$ The studied variables consisted of self-efficacy, hope, optimism, resilience and hardiness. The treatment variable was the positive psychological capital program and the dependent variable was the retention of nurses. For data collection, the researcher started with sending a consent letter to the directors of the studied hospitals to ask for permission to collect data. The Retention of Nurses Questionnaire was piloted with 30 nurses who were not the study subjects at Phramongkutklao Hospital.

The experimental group received the psychological capital program, whereas the control group did not. The program was provided to 20 nurses in the experimental group for 2 days ( 16 hours), while the control group did not receive any intervention. After implementing the program, the researcher asked both experimental and control group nurses to answer the Positive Psychological Capital Questionnaire again at postintervention and 2-week follow-up to provide sufficient time for those participating in the program to apply what they learned to their nursing practice and examine the sustainability of positive psychological 
The research was conducted under consideration of human rights and dignity, justice and rightness. After the research project was approved by the Institutional Review Board (IRB) Committee of the Army Medical Department, the researcher formally informed the director of the hospitals about the research objectives and asked for permission to collect the data. The subjects' rights were strictly protected using both verbal and written information. The consent form was signed by nurses participating in this study. They were informed that denial or discontinuing participation in this research would not affect them in any circumstances.

\section{Data analysis}

Descriptive statistics including percentage, maximum, minimum, mean and standard deviations of the scores in the Positive Psychological Capital Questionnaire were used to analyze the data. Content validity of the Retention of Nurses Questionnaire was performed using Index of Item-Objective congruence (IOC) by three experts totest validity between items and definitions specified. Discrimination index for each item of the Retention of Nurses Questionnaire was analyzed using Pearson' Product
Moment Correlation. The reliability of the Retention of Nurses Questionnaire was analyzed using Cronbach's alpha coefficient and the means of retention of nurses at experimental, post-experimental and follow-up phases were compared using F-test statistics from Two-way Repeated ANOVA Measurement.

\section{Results}

Most samples were aged 25 to 30 years $(22.9 \%)$, were female $(92.6 \%)$ and only $7.4 \%$ mere male. The majority of them were single (58.2\%), 37.7\% were married and the rest $(4.1 \%)$ were divorced, separated or widowed, respectively. In terms of education, $89 \%$ obtained a bachelor's degree and the remaining $11 \%$ had a Master's degree. Means and standard deviations of each aspect and the overall retention of nurse scores are presented in Table 1 . The average overall retention of nurses was high at 3.89 and the SD was 0.52 with maximum psychological aspect $(\mathrm{X}=4.08, \mathrm{SD}=0.60)$.

Table 2. shows that the average retention of nurses in the experimental group was higher than in the control group after completing the program and at follow-up with significance at .01 level.

Table 1. Means and standard deviations of each aspect and the overall retention of nurse scores

\begin{tabular}{|c|c|c|c|}
\hline Retention of nurse & $\mathrm{x}^{-}$ & SD & Level \\
\hline 1. Psychological aspect & 4.08 & 0.60 & High \\
\hline 2. Nurses' retention aspect & 3.85 & 0.62 & High \\
\hline 3. Norm aspect & 3.76 & 0.43 & High \\
\hline Overall & 3.89 & 0.52 & High \\
\hline
\end{tabular}

Table 2. Comparison between experimental and control groups in retention of nurses

\begin{tabular}{lccccc}
\hline Measurement phases & $\begin{array}{c}\text { Average } \\
\text { Experimental group }\end{array}$ & Control group & & & \\
& 2.76 & 2.80 & -.042 & .145 & -.342 \\
\hline Pre-experimental & 3.89 & 2.97 & -.452 & .134 & 1.432 \\
Postexperimental & 4.15 & 8.98 & -.775 & .146 & 3.656 \\
Follow-up & & & & & \\
\hline
\end{tabular}

$* p<.01$ 


\section{Discussion}

According to the research findings, the levels of positive psychological capital of nurses under the Ministry of Defense in the experimental group after receiving the program and at follow-up period were higher than in the control group which did not receive the program. The result was consistent with a study of Luthans et al. $(2007)^{(7)}$ which found that the level of positive psychological capital in the experimental group increased after the program, contributing to better working performance. ${ }^{(14,16)}$ The result can be explained in that this program was based on positive psychological concepts, positive organizational behaviors and group discussion. It developed individuals' psychological conditions linked to nursing practices. The guidelines to improve each component of the program included developing self-efficacy by promoting beliefs and confidence in one's own ability to obtain achievement to enhance their perception of success in the nursing profession. ${ }^{(17,18)}$ and developing hope, which is the process of setting goals and plans to achieve them. This leads to great commitment and determination to reach the set goals, developing optimism by creating positive expectations and reasoning to build up positive thinking toward achievement, developing resilience by improving and changing perceptions of the thinking process, emotions and behaviors to realize the value and abilities to return to the right track for success when facing challenges or barriers. Further, the program develops hardiness by improving working dedication and focusing on relaxation and stress management, contributing to greater retention among nurses. With these positive psychological assets, nurses would develop desirable thoughts and abilities to effectively plan and manage their work, believe in their ability to accomplish their goals, never easily give up to any challenges or difficulties and rapidly recover when facing any barrier, leading to greater working performance and success. ${ }^{(18,19)}$ The Retention of Nurses Questionnaire can also be used for nursing personnel in other organizations. According to the research findings, positive psychological capital is dynamic and motivating as shown by the increased level postintervention period when compared with the control group. Therefore, the program should be provided for nurses to reinforce desirable thoughts, emotions and behaviors to prepare them well prepared for their nursing practices and challenging missions.
However, studying and understanding the related concepts, theories and techniques used by psychological experts is highly recommended before applying the program to ensure best outcomes. The hospitals under the Ministry of Defense should consider positive psychological capital an important factor to develop nurses' psychological strengths and potential to prepare them for nursing practices. These psychological assets can push these hospitals forward to be leading organizations in improving nursing personnel' quality of work as specified by the Thai Nursing Council for optimal effectiveness and competitive advantages of the organizations. Thus, policies focusing on positive psychological capital development should be in place in addition to economic, human and social capital. ${ }^{(20)}$

\section{Recommendations for further research}

Many interesting dimensions and gaps of positive psychological capital and its development can be further studied such as other variables that can be explored including working happiness of professional nurses, effect of the positive psychological capital program on nurses in different contexts and settings such as other hospitals under the Ministry of Defense, government hospitals, hospitals of the Ministry of Public Health and private hospitals are recommended. The level of retention of nurses should be continuously followed up at one, three and six months after the program to evaluate sustainability of the program's effectiveness. Furthermore, qualitative data should be explored to gain more insights regarding this issue.

\section{References}

1. Sawangdee $\mathrm{K}$. The situation of nursing workforces in Thailand. Public Health System Research Journal 2008; 1: 40-6.

2. Boonthong T. Nurses and Personality Development. The subject module document of nursing profession experiences. Bangkok, Pisut Uksorn; 1990. p. 15-20.

3. Namfon N. Identity of nursing profession. Songkla: Tame Press; 1995. p. 5-12.

4. Kerdpitak P. Definition and significance of group counseling. course syllabus of professional experience of post graduates unit 1-6, 1st ed., Nonthaburi, Sukhothai Thammatirat University Press; 2003. p. 31-40. 
5. Srisuphan W. Shortage of Nurses. Newsletter of Thai Nursing Council. 11thYear; 2008. p. 50-60.

6. Kanjanawasi S. Applied Statistics. 3rd ed., Bangkok, Chulalongkorn University; 2002. p. 32-70.

7. Luthans F, Youssef CM, Avolio BJ. Psychological capital: Developing the human competitive edge. Oxford, UK, Oxford University Press; 2007. p. 40-60.

8. Luthans KW, Jensen SM. The linkage between psychological capital and commitment to organizational mission: A study of nurses. J Nurs Am 2005; 6: 304-10.

9. Luthans F, Avey JB, Patera J. Experimental analysis of a web-based training intervention to develop positive psychological capital. Acad Manage Learn Edu 2008; 7: 209-21.

10. Luthans F, Avolio BJ, Avey JB, Norman SM. Positive psychological capital: Measurement and relationship with performance and satisfaction. Journal of Personnel Psychology 2007; 60: 541-72.

11. Larson MD. Positive Psychological capital: a comparison with human and social capital and an analysis of a training intervention. A dissertation of The Graduate College at the University of Nebraska; 2004. p. 46-70.

12. Luthans, F. Psychological capital: Implications for HRD, retrospective analysis, and future directions. Hum Res Develop Quart 2012; 23: 1-8.

13. Luthans F, Avey JB, Avolio BJ, Peterson SJ. The development and resulting performance impact of positive psychological capital. Hum Res Develop Quart 2010; 21: 41-67.

14. Bandura, A. Social foundation of action: A social cognitive theory. New Jersey: Prentice-Hall; 1986. p. 15-35.

15. Li W. A Positive organizational behavior approach to work motivation: testing the core confidence model in China. Dissertation of Business Administration. Graduate School Bangkok University, Thailand; 2002. p. 30-70.

16. Manojlovich M. Promoting nurses' self efficacy: A leadership strategy to improve practice. J Nurs Am 2005; 35: 271-8.

17. Bandura A. Self efficacy: The exercise of control. New York: W.H. Freeman; 1997: 40-80.

18. Shukla A, Rai H. Interactive effects of psychological capital and perceived support in developing trust and commitment among Indian it executives. Employment Relations Record 2014; 14: 66-87.

19. Snyder CR. Hope theory: Rainbows in mind. Psycho$\log$ Inq 2002; 13: 249-2.

20. Chaleoykitti S. The model construction for developing positive psychological capital among professional nurse under the Ministry of Defense. J Health Res 2014; 28: 427-32. 